\title{
Research on the Measure Method of Netizens Complaint Theme Influence for Public Decision-making
}

\author{
Jianmin He ${ }^{1,2}$, Dongming Tian ${ }^{1, *}$ and Yezheng Liu ${ }^{1,2}$ \\ 1 School of Management, Hefei University of Technology, Hefei 230009, PR China \\ 2 Key Laboratory of Process Optimization and Intelligent Decision-making, Ministry of Education, \\ Hefei 230009, PR China \\ * Author to whom correspondence should be addressed; E-Mail: tian_dongming@126.com
}

Published: 13 November 2015

\begin{abstract}
Complaints about the formulation and implementation of public policy on online social network quickly become groups complaints through information gathering, frequently interaction, word-of-mouth communication and social emotional resonance. That can easily lead to public safety issues and bring troubles and challenges to the public decision-making. Therefore, assessing and managing groups complaints influence online social network has become a new problem for public policy decision-making organization to listen to and manage online groups complaints. This paper built the evaluation index system from four-dimensional perspective of complaint text's quality, transmission timeliness, user interaction degree and emotional resonance excited by emergency. Then, we established the dynamic influence measure model of online netizens complaint theme based on entropy weight model. The measure model was proved to be reasonable and effective by the empirical research of Sina Weibo data. It can effectively solve the measure problem of group complaints influence when the emergency excited social emotional resonance. The proposed four-dimensional dynamic influence measure model has important theoretical significance and practical value for public policy decision-maker on listening to online group complaints, understanding public opinion, and making public policy.
\end{abstract}

Keywords: Online social network; Emergency; Social emotional resonance; Influence measure; Entropy weight model 


\section{Introduction}

On the social network platform, complaints about the public policy formulation and implementation issues arise largely. This information through the information aggregation, frequent interaction, wordof-mouth and emotional resonance on online social network will lead to the outbreak of the network complaints. It brings difficulties and challenges in public management. China is under a period of social transformation, and there are various problems and contradictions. Emergency can easily provoke group complaints on online network, and it will lead to network public opinion through inducing social emotional resonance, which is harmful to social security and stability. For example, the PX event occurred in 2007 in Xiamen [1], is started from the condition that few people question the Xiamen PX project on the Internet, then became serious condition that many people strongly resist the PX project in the real space and it finally becomes a public management decision problem, and it brings severe challenges for government institutions to make public management decision. Network complaints of this kind induced by emotional resonance is a new problem in network public information security management decisions, is also a public hotspot research in the field of information management and decision support system.

With the growing popularity of the Internet, the awareness and ability of Internet users have been enhanced, and any public issues involving public interests will cause social attention. In order to fight for the right of information, participation and decision-making authority so as to highlight and stretch their own interests people will voice a variety of appeals and complaints on the Internet, and this public voice in government has important influence in public decision-making management process, including agenda setting, policy formulation and implementation. It is difficult to evaluate the information and its influence on the Internet because of the lack of sound management methods and tools, and this also complicate the public management decision-making process. It is necessary to study the evaluation and measurement method of the Internet, so as to provide an important theoretical basis and practical method for the government departments and related agencies to listen to the public complaints.

The evaluation of the Internet users' information influence is always a hot issue in the field of information management and information system research. Wu Xiaohua, Lin Chunying [2] for assessing the value of military intelligence, used the Shannon entropy value of information to support the military decision-making; ZHAO Hong, WANG Can [3] adopted the multiple linear models to evaluate micro-blog influence from the micro level choosing the forwarding volume as the evaluation index, in supporting of micro-blog marketing decision; Luo Xin [4] has chosen publish quantity, reply quantity, and forwarding quantity as the index to evaluate the micro-blog influence on emergencies, and this helps disposal of the dissemination of information on emergencies; Kien-Weng Tan et al. [5] has chosen guest features, emotion and communication, and community identification as index, to evaluate the influence of blog; Cha et al. [6] constructed the evaluation index system of micro-blog user influence choosing the number of the user's fans, the number of being forwarded and the number of users are put forward as well as other indicators based on the perspective of user behavior. Jianmin He et al. [7] uses the entropy weight model to construct a three-dimension index (the quality of the text, the communication time and the user's degree of interaction) to construct the measurement model of the impact of the information on the subject. 
In this paper, we study the influence measurement problem on Group complained subject information induced from social emotions affected by the sudden events of the resonance. We took the static and dynamic attribute data from four dimensions as Real-time monitoring and analysis index and the four dimensions are the quality of complaint context, spreading prescription, the degree of user interaction and emergency emotional resonance. We also constructed the online complaint subject information influence measurement model based on the information entropy method in order to explore the influence measurement methods on Group complained subject information induced from social emotions affected by the sudden events of the resonance and to provide a decision support method for public complaint information management.

\section{The influence evaluation indexes of complaint theme information on online social network}

\section{(1) The quality of complaint information}

Zhu Li et al. [8] found that the influence of bloggers is decided by post quality, and the authoritative bloggers tend to have an important impact on the quality of the post. Chien Chin Chen and You-De Tseng [9] found that reviews from authorities have higher quality, greater power, and there is a positive correlation between the number of product brands and the quality of the review information; LIAO Chenglin et al. [10] found that there is a positive correlation between the depth of online review and the usefulness of online reviews when studying the influence index of online reviews; Mudambi and Schuff [11] found that the length of comment has a direct impact on the usefulness of online comment, a long comment can attract customers to read carefully and eliminate customers' distrust.

According to the social network platform, this paper chooses the community level, the number of words in complaint content and the number of the key words in the text and other factors as a measure index to evaluate the quality of the online complaint information.

\section{(2) The transmission timeliness of the complaint text}

In the process of information dissemination, the degree of information flow is usually used as an evaluation index of the information timeliness. Fu Kan and Qiu Wanhua [12] measured the size of the bullwhip effect in supply chain by the aging entropy, and hold the opinion that the smaller the entropy aging the shorter the transfer time in the system, and transfer speed is fast; MA Jun et al. [13] took propagate speed (or the repeater frequency) as the index to evaluate the communication ability in micro blog in the research of the micro blog information dissemination ability; Lin Chen [14] has studied micro blogging individual information dissemination influence from the dissemination effect research perspective, and found propagation velocity (namely the repeater frequency) is an important indicator to measure micro blog information dissemination effect. These can be differentiated the same forwarding number situation under different inter individual information dissemination influence. In this paper, the forwarding frequency is used as an index to measure the time of the complaint text transmission timeliness. Forwarding frequency refers to the number of times that the text is forwarded to the text, the higher the frequency, the higher the speed of the complaint.

(3) The interaction degree of complaint text

The quality of the Complain text is an important factor affecting the dissemination of information [8-11], and the breadth and depth of the spread of complaining text decided the impact of the 
information. In social networks, the certain theme of the complaint information is easy to attract more attentions, and the information exchange between users can play a role in promoting the spread of the complaint, the higher the degree of interaction, the more participants and information, the greater the impact of compliant text. The existing research literature [3,4,6,7,15-19] evaluate the attention and interaction rate of microblog information based on the click number, forwarding number, recovery number, participant number etc. In this paper, we choose the click number of the complaints text, the forwarding number of complaints, the effective recovery number of complaints, the number of people involved in the complaint, the number of high level of reply and the number of forwarding as indexes to evaluate interaction degree of complaint text. Specially, the effective recovery number of complaints refers to the total number removed the number of against complain theme and the number of themes irrelevant to the subject; we only calculate the valid number, that is to say we only calculate the first time of the participation; the grades of people will affect the breadth of information transmitted, and for the same complaint information, the influence of subject information is completely different concerning the two different situations: first it was followed by a online social opinion leaders of high level and the second it was followed by a general user.

\section{(4) The emotional resonance degree excited emergency}

From the perspective of company manager, Jianmin He built online consumer complaint measure model based on complaint text's quality, transmission timeliness and user interaction degree. However, the influence on complaint text and public decision-making process from the emotional resonance of emergency haven't been considered. For example, there are two complaint theme $T_{l}$ and $T_{2}$.Coincidentally, one of them, $T_{1}$, was related to some emergencies. Because social emotion and the public interest are key focus for decision-making department in public decision-making process, they would try to ease the uncontrollable factor. Therefore, $T_{1}$ should be an important object for public decision-making. The process of $T_{l}$ forming may effect public decision-making seriously. Zhu Li and Cao Zhenfei [20] proposed structure box for the merchandise of public security group emergency and thought that the public voice in structure box is discrete. With the information spread of triggered emergency, the emotion of local public and the people involved would resonate and further gather potential discrete voice rapidly even break out. Neil Smelser [21] put forward 'Value-added theory' to illustrate the unexpected incident effect on group action broke. Liu Xuemei [22] found that the information spread reduced by emergency is an important factor for network public opinion resonance. Herbert Blumer [23] divided the aggregation into three stages: group run-in, group excitement and social infection. The process starts with idle rumour and then infects more people to resonate. Finally, with the emotion strengthened, group action would break up. As a result, the emotion resonance produced by emergency is important for online complaint theme influence. We measure emotion resonance degree from emergency information pageview, forward and user interaction. Just effective user interaction would be computed, that is to say, only one time is valid if interacted with subject one more time.

In social network, time would not influence complaint text quality. Then, we just take the forward frequency in given time into consideration when compute transmission timeliness. Therefore, we use the quality of complaint text, the transmission timeliness of complaint text as static indicators, while the degree of interaction about complaint text and emotion resonance of emergency as dynamic 
indicators. The evaluation index system of determination theme complaint text influence on online social network is shown in Table 1.

Table 1 The evaluation index system of complaint text influence on online social network.

\begin{tabular}{l|l|l}
\hline Index state & First grade index & Second grade index \\
\hline \multirow{2}{*}{ Static state } & The quality of complaint text & Rank of the complainer \\
\cline { 3 - 3 } & & Words number of complaint text \\
\cline { 2 - 3 } & The transmission timeliness of complaint text & Feywords number in complaint text \\
\hline \multirow{2}{*}{ Dynamic state } & The interaction degree of complaint text & Clicks number of complaint text \\
\cline { 3 - 3 } & & Forwarding number of the complaint text \\
\cline { 3 - 3 } & & The number of effective reply texts \\
\cline { 3 - 3 } & & Participants number of complaint text \\
\cline { 3 - 3 } & \multirow{2}{*}{$\begin{array}{l}\text { The emotional resonance degree excited by } \\
\text { emergency }\end{array}$} & The number of high rank repliers and forwarding people \\
\cline { 3 - 3 } & & Forwarding number of emergency information \\
& & Participants number of emergency information \\
\hline
\end{tabular}

\section{The measure model of the complain theme influence}

Shannon [24] firstly proposed the concept of "information entropy" to measure the information value and influence; YANG Hong et al. [25] used entropy theory to measure the information disclosure quality of listed companies; Cheng Qiyue et al. [26] used timeliness entropy to calculate the size of bullwhip effect in supply chain and evaluate the efficiency of command process; Ding Shifei et al. [27] applied some measure indexes such as fuzzy absolute entropy, relative entropy and cross entropy to measure the value of fuzzy information, where cross entropy is the interaction degree of information. Cai Zhenjie et al. [28] constructed environmental emergencies severity level of assessment methods based on the Information entropy theory, Entropy is obviously an effective method of measuring information and its influence.

From the thought of quality entropy, timeliness entropy, cross entropy and resonance entropy, this paper use four measure indexes including complaint text's quality, transmission timeliness, user interaction degree and emotional resonance emergencies degree to measure the influence of netizens complaint themes. The main idea of measuring the netizens complaint influence on certain theme is as follows: Firstly, builds the measure model of complaint theme influence with four-dimensional indicators based on the evaluation index system of complaint theme influence; then we construct the dynamic model to measure the influence of complaint theme based on the dynamic variation rule of the influence indexes with time changing on online social network.

\subsection{The definition of measure indexes of complaint theme influence}

Definition 1. On the social network, supposes that a complaint theme $T$ consists of $m$ complaints texts $A_{i}$ and $n$ emergencies $E_{j}, T=\left\{A_{1}, A_{2}, \ldots, A_{i}, \ldots, A_{m}, E_{1}, E_{2}, \ldots, E_{j}, \ldots, E_{n}\right\}(i=1,2, \ldots, m ; j=1,2, \ldots$, $n), A_{i}$ is the $i t h$ complaint text, $E_{j}$ is the $j t h$ emergency, $A_{i}=\left\{x_{i 1}, x_{i 2}, x_{i 3}, x_{i 4} ; y_{i 1}, y_{i 2}, y_{i 3}, y_{i 4}, y_{i 5}\right\}, E_{j}=\left\{z_{j l}\right.$, $\left.z_{j 2}, z_{j 3}\right\}$, Where $x_{i 1}, x_{i 2}, x_{i 3}, x_{i 4}$ denote the rank of complainer, words numbers of complaint text, the 
number of keywords in complaint text and forwarding frequency of complaint text respectively. The

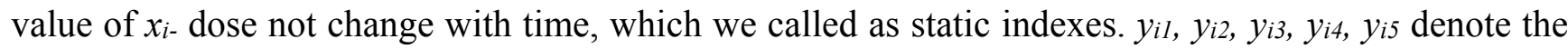
hits of complaint text, the number of being forwarding respectively, the number of effective reply texts, the number of participants, the number of high rank people who reply or forward, $z_{j} 1, z_{j} 2, z_{j 3}$ denote the hits of emergency, the number of being forwarding respectively, the number of interactive netizens. The value of $y_{i}$, $z_{j}$ - will change with time, which we called as dynamic indexes.

Definition 2. In order to evaluate the complaint theme information and its influence in a certain time period, we divide that time period into a number of intervals as $t_{1}, t_{2}, t_{3}, \ldots, t_{l}$. Suppose that complaint theme $T$ has $p_{i}$ complaint texts and $q_{i}$ emergency in $t_{i}(i=1,2,3, \ldots, l)$, $\sum_{i=1}^{l} p_{i}=m, \sum_{i=1}^{l} q_{i}=n\left(0 \leq p_{i} \leq m, 0 \leq q_{i} \leq n\right), T\left(t_{i}\right)=\left\{A_{1}\left(t_{i}\right), \ldots, A_{p}\left(t_{i}\right), \ldots, A_{p i}\left(t_{i}\right), E_{1}\left(t_{i}\right), \ldots, E_{q}\left(t_{i}\right), \ldots, E_{q i}\left(t_{i}\right)\right\}\left(0 \leq p \leq p_{i}\right.$, $\left.0 \leq q \leq q_{i}\right)$, where $A_{P}\left(t_{i}\right)=\left\{x_{p 1}\left(t_{i}\right), x_{p 2}\left(t_{i}\right), x_{p 3}\left(t_{i}\right), x_{p 4}\left(t_{i}\right), y_{p 1}\left(t_{i}\right), y_{p 2}\left(t_{i}\right), y_{p 3}\left(t_{i}\right), y_{p 4}\left(t_{i}\right), y_{p 5}\left(t_{i}\right)\right\}, E_{q}(t i)=\left\{z_{q 1}\left(t_{i}\right)\right.$, $\left.z_{q 2}\left(t_{i}\right), z_{q 3}\left(t_{i}\right)\right\}$.

For ease of description, we denote $x_{i-}, y_{i-}, z_{j}$ by sets, $x\left(t_{i}\right)=\left\{x_{p a}\left(t_{i}\right)\right\}(a=1, \ldots, 4) ; y\left(t_{i}\right)=\left\{y_{p b}\left(t_{i}\right)\right\}(b=1$, $\ldots, 5) ; z\left(t_{i}\right)=\left\{x_{q c}\left(t_{i}\right)\right\}(c=1, \ldots, 3)$. When observation interval $t_{i}$ comes to $t_{j},(1 \leq i, j \leq l ; i \leq j \leq l), A_{p}\left(t_{i}\right)$ becomes $A_{p}\left(t_{i \rightarrow j}\right)=\left\{x_{p 1}\left(t_{i}\right), x_{p 2}\left(t_{i}\right), x_{p 3}\left(t_{i}\right), x_{p 4}(t i), y_{p 1}\left(t_{j}\right), y_{p 2}\left(t_{j}\right), y_{p 3}\left(t_{j}\right), y_{p 4}\left(t_{j}\right), y_{p 5}\left(t_{j}\right)\right\}$, denotes the attribute value set $A_{p}\left(t_{i \rightarrow j}\right)$ in $t_{j}$ of the set $A_{p}\left(t_{i}\right)$ of complaint texts in $t_{i}$. specifically denotes the new level of interactivity of the text $A_{p}\left(t_{i}\right)$ under the observation period $t_{i}$ in the period $t_{j}$; Emergency $E_{q}\left(t_{i}\right)$ becomes $E_{q}\left(t_{i \rightarrow j}\right), E_{q}\left(t_{i \rightarrow j}\right)=\left\{z_{q 1}\left(t_{j}\right), z_{q 2}\left(t_{j}\right), z_{q 3}\left(t_{j}\right)\right\}$, denotes the attribute value set $E_{q}\left(t_{i \rightarrow j}\right)$ in $t_{j}$ of the set $E_{q}\left(t_{i}\right)$ of emergency in $t_{i}$. Specifically denotes the new level of resonance of the text $E_{q}\left(t_{i}\right)$ under the observation period $t_{i}$ in the period $t_{j}$.

There will be some new complaint texts and emergencies of complaint theme $T$ in $t_{j}$, suppose the quantity of new complaint texts is $g$ and the emergency is $k$, The set of complaint texts will $A_{p j}\left(t_{j}\right)=\{$ $\left.A_{1}\left(t_{i \rightarrow j}\right), \ldots, A_{p i}\left(t_{i \rightarrow j}\right), A_{p i+1}\left(t_{j}\right), \ldots, A_{p i+g}\left(t_{j}\right)\right\}$, and emergency will $E_{q j}\left(t_{j}\right)=\left\{E_{1}\left(t_{i \rightarrow j}\right), \ldots, E_{q i}\left(t_{i \rightarrow j}\right), E_{q i+1}\left(t_{j}\right)\right.$, ..., $\left.E_{q i+k}\left(t_{j}\right)\right\}$.

\subsection{The determination of index weight}

It is general to utilize the index weight coefficient to denote the importance of index which can be used to determine the indexes'importance of complaint text influence. XIE Chi and ZHONG Zan [29] believed the method of entropy weight model effectively avoids the interference of human factors, so that the index weight can be determined more scientific and the results more efficiently; ZHANG Sui et al. [30] considers that the calculation of the index using entropy weight model can measure the size of index information, thus ensuring the established indicators to reflect most of the original information, making evaluation results more realistic. Consequently, we consider comprehensively objective and subjective factors, use both expert grading method and entropy weight model. Determine the weight of first grade indexes using expert grading method and the weight of second grade indexes by entropy weight model. In order to reduce the effect of time on assignment, we do not consider the time factor in the weight of second grade indexes. The method of calculating indexes weight is given as below.

Step 1:Determine the weight of first grade indexes using expert grading method, select $n$ experts to percentile scores on the importance of the primary indicators, as follows: 
Table 2 expert scoring method to determine the right level index weight

\begin{tabular}{|c|c|c|c|c|c|}
\hline \multirow{2}{*}{ First grade index } & \multicolumn{4}{|c|}{ Experts } & \multirow{2}{*}{$\bar{S}$} \\
\hline & 1 & 2 & $\ldots$ & $\mathrm{n}$ & \\
\hline The quality of complaint text & $s_{11}$ & $s_{12}$ & $\cdots$ & $S_{1 n}$ & $\overline{s_{1}}=\frac{1}{n} \sum_{j=1}^{n} s_{1 j}$ \\
\hline $\begin{array}{l}\text { The transmission timeliness of complaint } \\
\text { text }\end{array}$ & $s_{21}$ & $s_{22}$ & $\cdots$ & $s_{2 n}$ & $\overline{s_{2}}=\frac{1}{n} \sum_{j=1}^{n} s_{2 j}$ \\
\hline The interaction degree of complaint text & $s_{31}$ & $s_{32}$ & $\ldots$ & $s_{3 n}$ & $\overline{s_{3}}=\frac{1}{n} \sum_{j=1}^{n} s_{3 j}$ \\
\hline $\begin{array}{l}\text { The emotional resonance degree excited by } \\
\text { emergency }\end{array}$ & $s_{41}$ & $s_{42}$ & $\ldots$ & $S_{4 n}$ & $\overline{s_{4}}=\frac{1}{n} \sum_{j=1}^{n} s_{4 j}$ \\
\hline
\end{tabular}

Therefore,the weight radio of complaint text's quality, transmission timeliness, user interaction degree and emotional resonance emergencies degree, after normalization to get the weight of level indicators is $\overline{s_{1}}: \overline{s_{2}}: \overline{s_{3}}: \overline{s_{4}}$, Normalization obtained after an index weight is $\alpha_{1}, \alpha_{2}, \alpha_{3}, \alpha_{4}$, where $\alpha_{i}=\overline{s_{i}} / \sum_{i=1}^{4} \overline{s_{i}}, \sum_{i=1}^{4} \alpha_{i}=1$.

Step 2. According to the Entropy weight method to calculate the weight of second grade indexes Proceed as follows:

(1)Build the initial matrix

$$
D=\left[\begin{array}{ccccccccc}
x_{11} & \cdots & x_{14} & y_{11} & \cdots & y_{15} & z_{11} & \cdots & z_{13} \\
x_{21} & \cdots & x_{24} & y_{21} & \cdots & y_{25} & z_{21} & \cdots & z_{23} \\
\vdots & \vdots & \vdots & \vdots & \vdots & \vdots & \vdots & \vdots & \vdots \\
x_{i 1} & \cdots & x_{i 4} & y_{i 1} & \cdots & y_{i 5} & z_{i 1} & \cdots & z_{i 3} \\
\vdots & \vdots & \vdots & \vdots & \vdots & \vdots & \vdots & \vdots & \vdots \\
x_{m 1} & \cdots & x_{m 4} & y_{m 1} & \cdots & y_{m 5} & z_{m 1} & \cdots & z_{m 3}
\end{array}\right]
$$

(2) Data dimensionless processing. As each index's dimension is different, we need to normalize the data for comparison. In this paper, all indexes are positive indexes, and the greater index value is better. The normalization method is given as the following formulas.

$$
\begin{aligned}
& x_{i a}^{\prime}=\frac{x_{i a}-\min _{a}\left(x_{i a}\right)}{\max _{a}\left(x_{i a}\right)-\min _{a}\left(x_{i a}\right)}(i=1,2, \cdots m ; a=1, \cdots, 4) \\
& y_{i b}^{\prime}=\frac{y_{i b}-\min _{b}\left(y_{i b}\right)}{\max _{b}\left(y_{i b}\right)-\min _{b}\left(y_{i b}\right)}(i=1,2, \cdots m ; b=1, \cdots, 5) \\
& z_{i c}^{\prime}=\frac{z_{i c}-\min _{c}\left(z_{i c}\right)}{\max _{c}\left(z_{i c}\right)-\min _{c}\left(z_{i c}\right)}(i=1,2, \cdots m ; c=1, \cdots, 3)
\end{aligned}
$$

The matrix after normalizing can be expressed by

$$
D^{\prime}=\left[\begin{array}{ccccccccc}
x_{11}^{\prime} & \cdots & x_{14}^{\prime} & y_{11}^{\prime} & \cdots & y_{15}^{\prime} & z_{11}^{\prime} & \cdots & z_{13}^{\prime} \\
x_{21}^{\prime} & \cdots & x_{24}^{\prime} & y_{21}^{\prime} & \cdots & y_{25}^{\prime} & z_{21}^{\prime} & \cdots & z_{23}^{\prime} \\
\vdots & \vdots & \vdots & \vdots & \vdots & \vdots & \vdots & \vdots & \vdots \\
x_{i 1}^{\prime} & \cdots & x_{i 4}^{\prime} & y_{i 1}^{\prime} & \cdots & y_{i 5}^{\prime} & z_{i 1}^{\prime} & \cdots & z_{i 3}^{\prime} \\
\vdots & \vdots & \vdots & \vdots & \vdots & \vdots & \vdots & \vdots & \vdots \\
x_{m 1}^{\prime} & \cdots & x_{m 4}^{\prime} & y_{m 1}^{\prime} & \cdots & y_{m 5}^{\prime} & z_{m 1}^{\prime} & \cdots & z_{m 3}^{\prime}
\end{array}\right]
$$


(3) Calculate the index's proportion $p_{i a}(x) 、 p_{i b}(y)$

$$
\begin{aligned}
& p_{i a}(x)=\frac{x_{i a}^{\prime}}{\sum_{i=1}^{m} x_{i a}^{\prime}}(i=1,2, \cdots m ; a=1, \cdots, 4) \\
& p_{i b}(y)=\frac{y_{i b}^{\prime}}{\sum_{i=1}^{m} y_{i b}^{\prime}}(i=1,2, \cdots m ; b=1, \cdots, 5) \\
& p_{i c}(z)=\frac{z_{i c}^{\prime}}{\sum_{i=1}^{m} z_{i c}^{\prime}}(i=1,2, \cdots m ; c=1, \cdots, 3)
\end{aligned}
$$

(4) Calculate the value of each index's entropy $H_{a}\left(H_{b}, H_{c}\right)$

$H_{a}=-k \sum_{i=1}^{m} p_{i a}(x) \ln p_{i a}(x)$, where $k=1 / \ln m$, when $p_{i a}=0, p_{i a} \ln p_{i a}=0$

The value of $H_{b}, H_{c}$ can be calculated in a similar way.

(5) The weight of each index.

$$
w_{a}=\frac{1-H_{a}}{3-\sum_{a=1}^{3} H_{a}}, w_{b}=\frac{1-H_{b}}{5-\sum_{b=1}^{5} H_{b}}, w_{c}=\frac{1-H_{c}}{3-\sum_{c=1}^{3} H_{c}}
$$

and $\sum_{a=1}^{3} w_{a}=1, \sum_{b=1}^{5} w_{b}=1, \sum_{c=1}^{3} w_{c}=1$ because the transmission timeliness of complaint text only complain forwarding frequency of complaint text, so $w_{a=4}=1$.

Thus, the weight radio of complaint text's quality, transmission timeliness, user interaction degree and emotional resonance emergencies degree, after normalization to get the weight of level indicators is $\alpha_{1}, \alpha_{2}, \alpha_{3}, \alpha_{4}$, and Comprehensive weight of the second index is $w_{a}^{\prime}=\alpha_{1} w_{a}(a=1 \cdots 3), w_{a=4}^{\prime}=\alpha_{2} w_{a=4}=\alpha_{2}, w_{b}^{\prime}=\alpha_{3} w_{b}(b=1 \cdots 5), w_{c}^{\prime}=\alpha_{4} w_{c}(c=1 \cdots 3)$.

\subsection{The dynamic model of complaint theme influence}

Suppose that each complaint text has the same influence index, the method of measuring arbitrary complaint text influence for the same complaint theme without considering time factor is given as below.

For an arbitrary complaint text $A_{i}$, the set of attribute index is $A_{i}=\left\{x_{i 1}, x_{i 2}, x_{i 3}, x_{i 4} ; y_{i 1}, y_{i 2}, y_{i 3}, y_{i 4}\right.$, $\left.y_{i 5}\right\}$, emergency $E_{j}$, the set of attribute index is $E_{j}=\left\{z_{j 1}, z_{j 2}, z_{j 3}\right\}$, the quality of complaint text $A_{i}$ is $I q$ $\left(A_{i}\right)$, the timeliness of complaint text $A_{i}$ is $I t\left(A_{i}\right)$, the interaction degree of complaint text $A_{i}$ is $I c\left(A_{i}\right)$ and the emotional resonance degree of $E_{j}$ is $\operatorname{Ir}\left(E_{j}\right)$.Their calculation formulas are given below respectively.

$$
\begin{aligned}
& I q\left(A_{i}\right)=\sum_{a=1}^{3} w_{a}^{\prime} x_{i a} \\
& I t\left(A_{i}\right)=w_{a=4}^{\prime} x_{i 4}
\end{aligned}
$$




$$
\begin{aligned}
& \operatorname{Ic}\left(A_{i}\right)=\sum_{b=1}^{5} w_{b}^{\prime} y_{i b} \\
& \operatorname{Ir}\left(E_{j}\right)=\sum_{c=1}^{3} w_{c}^{\prime} z_{j c}
\end{aligned}
$$

The influence of complaint text $A_{i}$ is $\operatorname{In}\left(A_{i}\right)$ :

$$
\operatorname{In}\left(A_{i}\right)=\operatorname{Iq}\left(A_{i}\right)+\operatorname{It}\left(A_{i}\right)+\operatorname{Ic}\left(A_{i}\right)
$$

The influence of emotional resonance under Emergency $E_{j}$ is $\operatorname{In}\left(E_{j}\right)$ :

$$
\operatorname{In}\left(E_{j}\right)=\operatorname{Ir}\left(E_{j}\right)
$$

Therefore, without considering time factor, the influence of complaint theme $T$ is $\operatorname{In}(T)$ :

$$
\operatorname{In}(T)=\sum_{i=1}^{m} \operatorname{In}\left(A_{i}\right)+\sum_{j=1}^{n} \operatorname{In}\left(E_{j}\right)
$$

Formula (7) is the method of measuring the influence of complaint theme without considering time factor. To observe the changing process of complaint theme's influence, the time factor should be considered. The influence of complaint theme in arbitrary $t_{j}(j=1,2, \ldots, l)$ are calculated with the influence caused by the changing of the interaction degree of all complaint texts before $t_{j}$ plus the influence of new complaint texts in $t_{j}$.

Suppose that the set of complaint texts in measurable time section is $P=\left\{p_{1}, p_{2}, \cdots, p_{l}\right\}, \sum_{i=1}^{l} p_{i}=m\left(0 \leq p_{i} \leq m\right) \quad$.the $\quad$ set $\quad$ of emergency is $Q=\left\{q_{1}, q_{2}, \cdots, q_{l}\right\}, \sum_{i=1}^{l} q_{i}=m\left(0 \leq q_{i} \leq n\right)$.

The dynamic measurement model of complaint context's influence is given as Formula (8).

$$
\begin{aligned}
\operatorname{In}\left(A_{t_{j}}\right) & =\sum_{i=1}^{j-1} \sum_{p=1}^{p_{i}} \operatorname{Ic}\left[A_{p}\left(t_{i \rightarrow j}\right)\right]+\sum_{p=1}^{p_{j}} \operatorname{In}\left[A_{p}\left(t_{j}\right)\right] \\
& =\sum_{i=1}^{j-1} \sum_{p=1}^{p_{i}} \operatorname{Ic}\left[A_{p}\left(t_{i \rightarrow j}\right)\right]+\sum_{p=1}^{p_{j}}\left\{\operatorname{Iq}\left[A_{p}\left(t_{j}\right)\right]+\operatorname{It}\left[A_{p}\left(t_{j}\right)\right]+\operatorname{Ic}\left[A_{p}\left(t_{j}\right)\right]\right\}
\end{aligned}
$$

The dynamic measurement model of emergency emotional resonance influence is given as Formula (9).

$$
\begin{aligned}
\operatorname{In}\left(E_{t_{j}}\right) & =\sum_{i=1}^{j-1} \sum_{q=1}^{q_{i}} \operatorname{Ir}\left[E_{q}\left(t_{i \rightarrow j}\right)\right]+\sum_{q=1}^{q_{j}} \operatorname{In}\left[E_{q}\left(t_{j}\right)\right] \\
& =\sum_{i=1}^{j-1} \sum_{q=1}^{q_{i}} \operatorname{Ir}\left[E_{q}\left(t_{i \rightarrow j}\right)\right]+\sum_{q=1}^{q_{j}} \operatorname{Ir}\left[E_{q}\left(t_{j}\right)\right]
\end{aligned}
$$

The dynamic measurement model of complaint theme's influence is given as Formula (10).

$$
\operatorname{In}\left(T_{t_{j}}\right)=\operatorname{In}\left(A_{t_{j}}\right)+\operatorname{In}\left(E_{t_{j}}\right)
$$




\section{Case analysis and discussions}

\subsection{Data collection and pretreatment}

In this paper, we choose public complaints about "food security" as complaint theme $T$, and collect the experimental data through "Sina Weibo" platform. The observation and data collection period is a year from Mar. 1,2013 to Feb. 28,2014. Due to the rapid updating and transmission of information on Sina Weibo, we select "one day" as minimum observation granularity, record the daily data of complaint information and the changes of their indexes.

Data collection. We obtain the required data from the data interface of "Sina Weibo" platform (http://open.weibo.com/wiki/\%E5\%BE\%AE\%E5\%8D\%9AAPI), the resulting data are divided into two categories: one is user micro blog data. The data includes complainer's ID, complainer's rank, the quantity of complainer's fans, complaint text content, the time of publication, the number of weibo been forwarded, forwarding people's rank, the time of weibo been forwarded ,the number of reviews , reviewer's rank and the time of weibo been reviewed. The other is the related data about the emergencies on Sina Weibo associated with the complaint theme. When one unexpected event occurs, it will produce one or more discussion topics related to it, some netizens gathered by these topics will interact and discuss with each other frequently though expressing their views or venting their discontent. Since the weibo complaint topics around the emergency prone to stimulate Internet users emotional resonance, it's necessary to collect these data, mainly includes the number of weibo, the number of reading, the number of discussions, the number of fans, the number of weibo been forwarded, comments, the number of comments and reviewer's ID.

Data processing and explanation. In order to verify the validity of the model method, we need to process the raw data, such as the following:

1) Complainer's rank. Sina Weibo platform viewed the user's experience as the proof for their rank, we can employ users' rank instead of complainer's rank.

2) Keywords in complaint text. Keywords refer to the words related to complaint theme in the text.

3) Forwarding frequency of complaint text. It is the ratio of the number of text forwarded to the time within 4 hours after complaint text released.

4) The clicks of complaint text. As the number of weibo messages' words cannot surpass 140 and they are very concise, users can browse information without hitting. If one registered user releases a complaint text, afterwards all his active fans would see this information. Therefore, we can use the number of active fans as the hits of complaint text.

5) The number of valid responses to complaint text. It is the quantity of response texts with comprehensive consideration for the quality of response texts.

6) The number of participants. It refers to the sum of people who validly participate in the theme discussion with only one response.

7) The number of reply and forwarding of high rank people. As the level of general users on Sina weibo is not beyond level 15, so we can consider users whose level is beyond 15 as high rank users, and calculate the total as the parameter value. 
8) The hits of emergency. It refers to the number of reading about weibo text topics related to the emergency. If there are more than one weibo text topic related, we need take the sum of all topics reading.

9) The number of emergency text been forwarded. It is the total of the number of related weibo text been forwarded.

10) The number of participants interacting with emergency topics. It refers to the sum of people who participate in the weibo topics related to emergency with only one response.

After data processing, we select partial data related to the complaint theme $T$ "food security" in a period of t79(May 18,2013), as shown in Table 3, 4.

Table 3. The list of partial data related to the theme $T$ in a period of $t 79$ (May 18,2013).

\begin{tabular}{|c|c|c|c|c|c|c|c|c|c|}
\hline $\begin{array}{l}\text { First } \\
\text { grade } \\
\text { index }\end{array}$ & \multicolumn{3}{|c|}{$\begin{array}{l}\text { The quality of complaint text } \\
\qquad I \boldsymbol{q}\end{array}$} & \multirow{2}{*}{$\begin{array}{c}\text { The } \\
\text { transmission } \\
\text { timeliness of } \\
\text { complaint text It } \\
\\
\text { Forwarding } \\
\text { frequency of } \\
\text { complaint text } \\
\text { (item } / \mathrm{h} \text { ) } \\
\mathbf{x}_{4}\end{array}$} & \multicolumn{5}{|c|}{$\begin{array}{l}\text { The interaction degree of complaint text } \\
\qquad \text { Ic }\end{array}$} \\
\hline $\begin{array}{c}\text { Complai } \\
\text { nt text } \\
\mathrm{A}_{\mathrm{i}}\left(\mathrm{t}_{79}\right)\end{array}$ & $\begin{array}{c}\text { Rank of the } \\
\text { complainer } \\
\mathbf{x}_{1}\end{array}$ & $\begin{array}{c}\text { Words } \\
\text { number } \\
\text { of } \\
\text { compla } \\
\text { int text } \\
\mathbf{x}_{2}\end{array}$ & $\begin{array}{c}\text { Keywords } \\
\text { number in } \\
\text { complaint } \\
\text { text } \\
\mathbf{x} 3\end{array}$ & & $\begin{array}{l}\text { Clicks } \\
\text { number } \\
\text { of } \\
\text { complai } \\
\text { nt text } \\
\text { y1 }\end{array}$ & $\begin{array}{l}\text { Forwardin } \\
\mathrm{g} \text { number } \\
\text { of the } \\
\text { complaint } \\
\text { text } \\
\mathbf{y}_{2}\end{array}$ & $\begin{array}{l}\text { The } \\
\text { number of } \\
\text { effective } \\
\text { reply texts } \\
\mathbf{y}_{\mathbf{3}}\end{array}$ & $\begin{array}{c}\text { Particip } \\
\text { ants } \\
\text { number } \\
\text { of } \\
\text { complai } \\
\text { nt text } \\
\mathbf{y} 4\end{array}$ & $\begin{array}{c}\text { The } \\
\text { number of } \\
\text { high rank } \\
\text { repliers } \\
\text { and } \\
\text { forwardin } \\
\text { g people } \\
\mathbf{y}_{5}\end{array}$ \\
\hline $\mathrm{A}_{1}(\mathrm{t} 79)$ & 6 & 120 & 11 & 2.5 & 139 & 5 & 5 & 6 & 10 \\
\hline $\mathrm{A}_{2}(\mathrm{t} 79)$ & 11 & 137 & 12 & 3.25 & 289 & 2 & 2 & 10 & 13 \\
\hline $\mathrm{A}_{3}(\mathrm{t} 79)$ & 15 & 115 & 10 & 28.75 & 36461 & 20 & 25 & 90 & 115 \\
\hline $\mathrm{A}_{4}\left(\mathrm{t}_{79}\right)$ & 5 & 106 & 7 & 1.25 & 68 & 0 & 0 & 2 & 5 \\
\hline $\mathrm{A}_{5}\left(\mathrm{t}_{79}\right)$ & 10 & 119 & 9 & 0.5 & 430 & 1 & 1 & 1 & 2 \\
\hline $\mathrm{A}_{6}\left(\mathrm{t}_{79}\right)$ & 7 & 113 & 8 & 3.75 & 127 & 2 & 2 & 8 & 15 \\
\hline $\mathrm{A}_{7}\left(\mathrm{t}_{79}\right)$ & 9 & 96 & 9 & 5.25 & 316 & 5 & 7 & 12 & 21 \\
\hline $\mathrm{A}_{8}(\mathrm{t} 79)$ & 5 & 137 & 11 & 0 & 101 & 0 & 0 & 0 & 0 \\
\hline $\mathrm{A}_{9}(\mathrm{t} 79)$ & 7 & 93 & 10 & 1.25 & 218 & 2 & 2 & 4 & 5 \\
\hline $\mathrm{A}_{10}\left(\mathrm{t}_{79}\right)$ & 15 & 138 & 13 & 239 & 2361000 & 207 & 305 & 677 & 956 \\
\hline $\mathrm{A}_{11}\left(\mathrm{t}_{79}\right)$ & 4 & 128 & 9 & 0.5 & 87 & 0 & 0 & 0 & 2 \\
\hline $\mathrm{A}_{12}\left(\mathrm{t}_{79}\right)$ & 7 & 115 & 8 & 2.25 & 97 & 5 & 5 & 4 & 9 \\
\hline $\mathrm{A}_{13}\left(\mathrm{t}_{79}\right)$ & 11 & 122 & 9 & 2.75 & 356 & 7 & 7 & 12 & 11 \\
\hline $\mathrm{A}_{14}\left(\mathrm{t}_{79}\right)$ & 9 & 86 & 8 & 5.25 & 417 & 9 & 9 & 17 & 21 \\
\hline $\mathrm{A}_{15}\left(\mathrm{t}_{79}\right)$ & 10 & 139 & 10 & 8.75 & 297 & 5 & 5 & 24 & 35 \\
\hline $\mathrm{A}_{16}\left(\mathrm{t}_{79}\right)$ & 7 & 106 & 6 & 1.25 & 142 & 0 & 0 & 2 & 5 \\
\hline $\mathrm{A}_{17}\left(\mathrm{t}_{79}\right)$ & 5 & 93 & 8 & 0 & 54 & 0 & 0 & 0 & 0 \\
\hline $\mathrm{A}_{18}\left(\mathrm{t}_{79}\right)$ & 11 & 122 & 9 & 2 & 301 & 2 & 2 & 7 & 8 \\
\hline $\mathrm{A}_{19}\left(\mathrm{t}_{79}\right)$ & 8 & 96 & 10 & 1.75 & 72 & 0 & 0 & 3 & 7 \\
\hline $\mathrm{A}_{20}\left(\mathrm{t}_{79}\right)$ & 11 & 126 & 12 & 3.75 & 121 & 3 & 3 & 11 & 15 \\
\hline $\mathrm{A}_{21}\left(\mathrm{t}_{79}\right)$ & 15 & 128 & 10 & 109.25 & 1571003 & 67 & 111 & 389 & 437 \\
\hline $\mathrm{A}_{22}\left(\mathrm{t}_{79}\right)$ & 7 & 119 & 6 & 1.25 & 94 & 0 & 0 & 2 & 5 \\
\hline $\mathrm{A}_{23}\left(\mathrm{t}_{79}\right)$ & 7 & 120 & 11 & 4.5 & 69 & 5 & 5 & 12 & 18 \\
\hline $\mathrm{A}_{24}\left(\mathrm{t}_{79}\right)$ & 4 & 103 & 8 & 0 & 53 & 0 & 0 & 0 & 0 \\
\hline $\mathrm{A}_{25}\left(\mathrm{t}_{79}\right)$ & 7 & 85 & 8 & 1.25 & 176 & 1 & 1 & 3 & 5 \\
\hline $\mathrm{A}_{26}\left(\mathrm{t}_{79}\right)$ & 8 & 98 & 12 & 2.25 & 216 & 4 & 4 & 7 & 9 \\
\hline $\mathrm{A}_{27}\left(\mathrm{t}_{79}\right)$ & 6 & 80 & 6 & 0 & 42 & 1 & 1 & 0 & 0 \\
\hline $\mathrm{A}_{28}\left(\mathrm{t}_{79}\right)$ & 5 & 106 & 7 & 0.5 & 37 & 0 & 0 & 0 & 2 \\
\hline $\mathrm{A}_{29}\left(\mathrm{t}_{79}\right)$ & 10 & 79 & 5 & 7.5 & 365 & 8 & 15 & 23 & 30 \\
\hline
\end{tabular}




\begin{tabular}{|c|c|c|c|c|c|c|c|c|c|}
\hline $\mathrm{A}_{30}\left(\mathrm{t}_{79}\right)$ & 4 & 120 & 9 & 0 & 25 & 0 & 0 & 0 & 0 \\
\hline$\ldots \ldots$ & $\ldots \ldots$ & $\ldots \ldots$ & $\ldots \ldots$ & $\ldots \ldots$ & $\ldots \ldots$ & $\ldots \ldots$ & $\ldots \ldots$ & $\ldots \ldots$ & $\ldots \ldots$ \\
\hline
\end{tabular}

Table 4. The list of emergency data related to the theme $\mathrm{T}$ in a period of $\mathrm{t} 79$ (May 18,2013).

\begin{tabular}{|c|c|c|c|}
\hline \multirow{2}{*}{$\begin{array}{l}\text { First grade } \\
\text { index }\end{array}$} & \multicolumn{3}{|c|}{ Emotional resonance excited by emergency $\mathbf{I r}$} \\
\cline { 2 - 4 } & $\begin{array}{c}\text { Clicks number of } \\
\text { ement data }\end{array}$ & $\begin{array}{c}\text { Forwarding number of } \\
\text { emergency information } \\
\mathbf{z}_{\mathbf{1}}\end{array}$ & $\begin{array}{c}\text { Participants number of } \\
\text { emergency information } \\
\mathbf{z}_{\mathbf{3}}\end{array}$ \\
\hline$E_{1}\left(t_{79}\right)$ & 36673850 & 528722 & 193352 \\
\hline
\end{tabular}

\subsection{The calculation of complaint theme influence}

In this paper, we first use the expert scoring method to determine the first grade index weight, and then employ the entropy weight method to calculate the weight of the second grade indexes, and finally get the comprehensive weight of the two grade indexes. The results are shown in Table 5:

Table 5.The weight of first grade indexes and second grade indexes.

\begin{tabular}{|c|c|c|c|}
\hline First grade index & weight & Second grade index & $\begin{array}{c}\text { comprehensive } \\
\text { weight }\end{array}$ \\
\hline \multirow{3}{*}{ The quality of complaint text $\boldsymbol{I} \boldsymbol{q}$} & \multirow{3}{*}{0.1} & Rank of the complainer $\mathbf{x} 1$ & 0.0643 \\
\hline & & Words number of complaint text $\mathbf{x}_{\mathbf{2}}$ & 0.0124 \\
\hline & & Keywords number in complaint text $\mathbf{x}_{\mathbf{3}}$ & 0.0233 \\
\hline $\begin{array}{l}\text { The transmission timeliness of } \\
\text { complaint text } \boldsymbol{I t}\end{array}$ & 0.15 & Forwarding frequency of complaint text $\mathbf{x}_{4}$ & 0.15 \\
\hline \multirow{5}{*}{$\begin{array}{l}\text { The interaction degree of } \\
\text { complaint text } \boldsymbol{I c}\end{array}$} & \multirow{5}{*}{0.45} & Clicks number of complaint text $\mathbf{y}_{\mathbf{1}}$ & 0.1179 \\
\hline & & Forwarding number of the complaint text $\mathbf{y}_{\mathbf{2}}$ & 0.0819 \\
\hline & & The number of effective reply texts $\mathbf{y}_{\mathbf{3}}$ & 0.0864 \\
\hline & & Participants number of complaint text $\mathbf{y}_{4}$ & 0.0796 \\
\hline & & The number of high rank repliers and forwarding people $\mathbf{y}_{\mathbf{5}}$ & 0.0842 \\
\hline \multirow{3}{*}{$\begin{array}{c}\text { The emotional resonance degree } \\
\text { excited by emergency } \boldsymbol{I r}\end{array}$} & \multirow{3}{*}{0.3} & Clicks number of emergency information $\mathbf{z} \mathbf{1}$ & 0.1245 \\
\hline & & Forwarding number of emergency information $\mathbf{z}_{2}$ & 0.0852 \\
\hline & & Participants number of emergency information $\mathbf{z}_{3}$ & 0.0903 \\
\hline total & 1 & total & 1 \\
\hline
\end{tabular}

As can be seen from Table 5, the degree of interaction about complaint text and the degree of resonance caused by emergency in first grade index have even greater impact on the influence of complaint theme. In second indexes, complainer's rank has greatest impact on the quality of complaint text $I q$, and the hits of complaint text has greatest impact on the degree of interaction about complaint text $I c$, the hits of emergency has greatest impact on the degree of resonance caused by emergency $I r$.

Based on the dynamic measure method of netizens complaint theme influence, associated with the weights of indexes in Table 5 and post-processing weibo data related to complaint theme $T$, we calculate with the value of complaint theme influence at every stage, and generate influence change diagram. The results are shown in Figure 1. 
Figure 1. The influence changing trend of complaint themes T" food security".

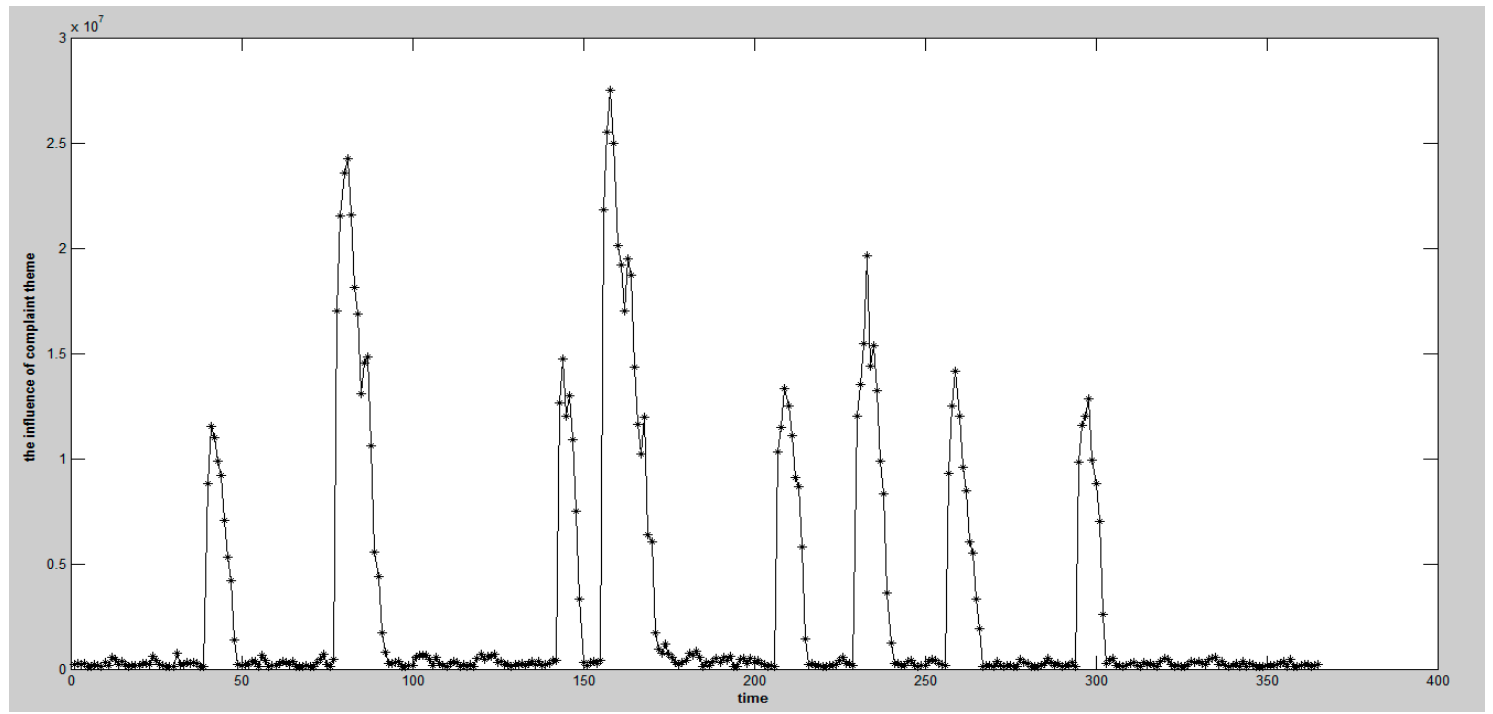

In order to more directly observe the effects of emotional resonance coursed by emergencies on complaint theme influence, we select "cadmium rice" event and "Taiwan Datong evil oil" event, both under the complaint theme "food security", obtain the complaint text data during two periods from May 10,2013 to Jun. 9,2013 and from Oct. 10,2013 to Nov. 9,2013. Not considering the index of emotional resonance coursed by emergency $I r$, and correcting the weights of first grade indexes and the corresponding second indexes of the quality of complaint text $I q$, the transmission timeliness of complaint text $I t$ and the degree of interaction about complaint text $I c$, we recalculate the influence of complaint theme. Then we compare the new value to the value considered the emotional resonance coursed by emergency. The results are shown in Figure 2 and Figure 3.

Figure 2. The complaint theme influence comparison in "cadmium rice "event procedure in the situations of considering and not considering the emotional resonance coursed by emergency.

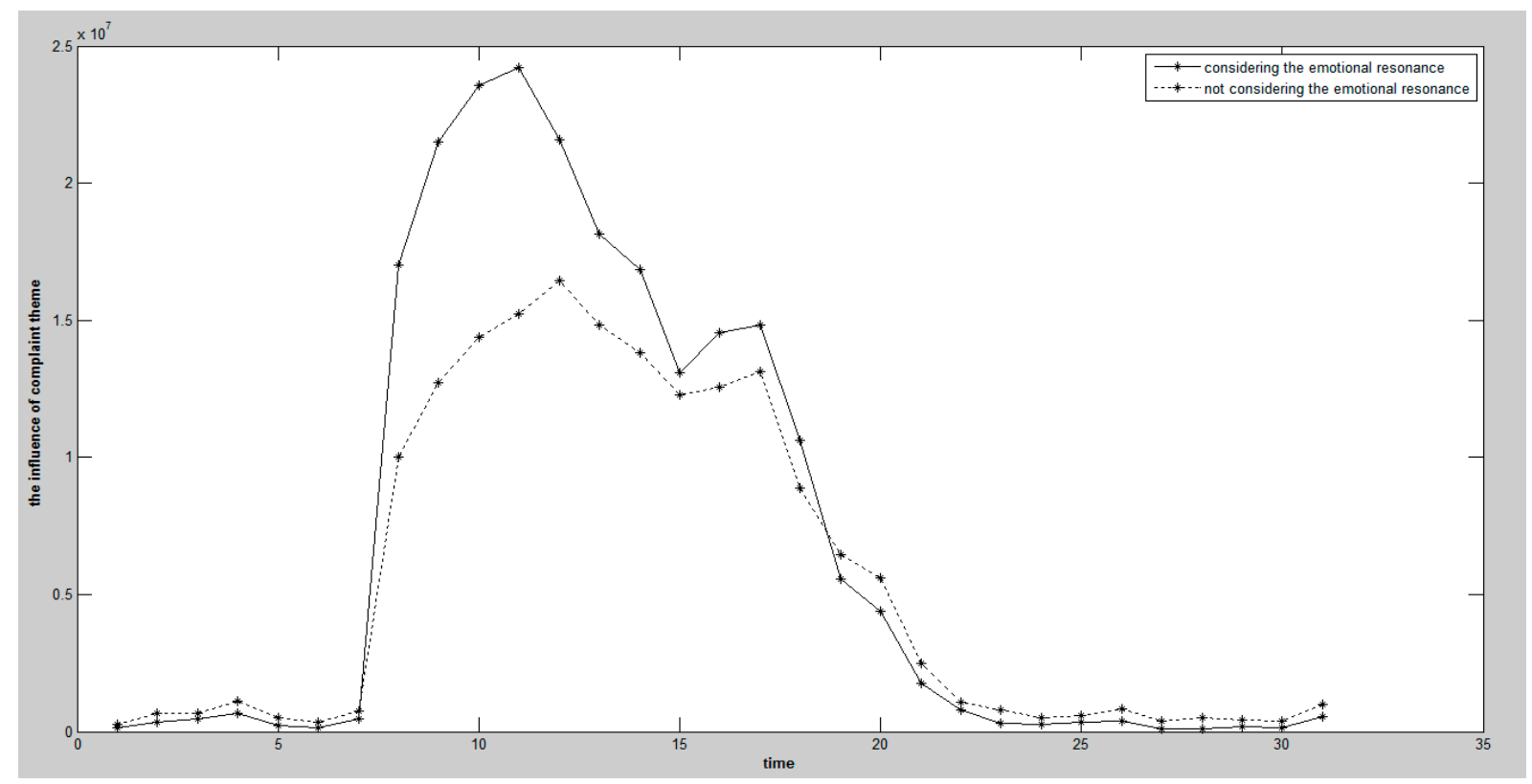


Figure 3. The complaint theme influence comparison in "Taiwan Datong evil oil "event procedure in the situations of considering and not considering the emotional resonance coursed by emergency.

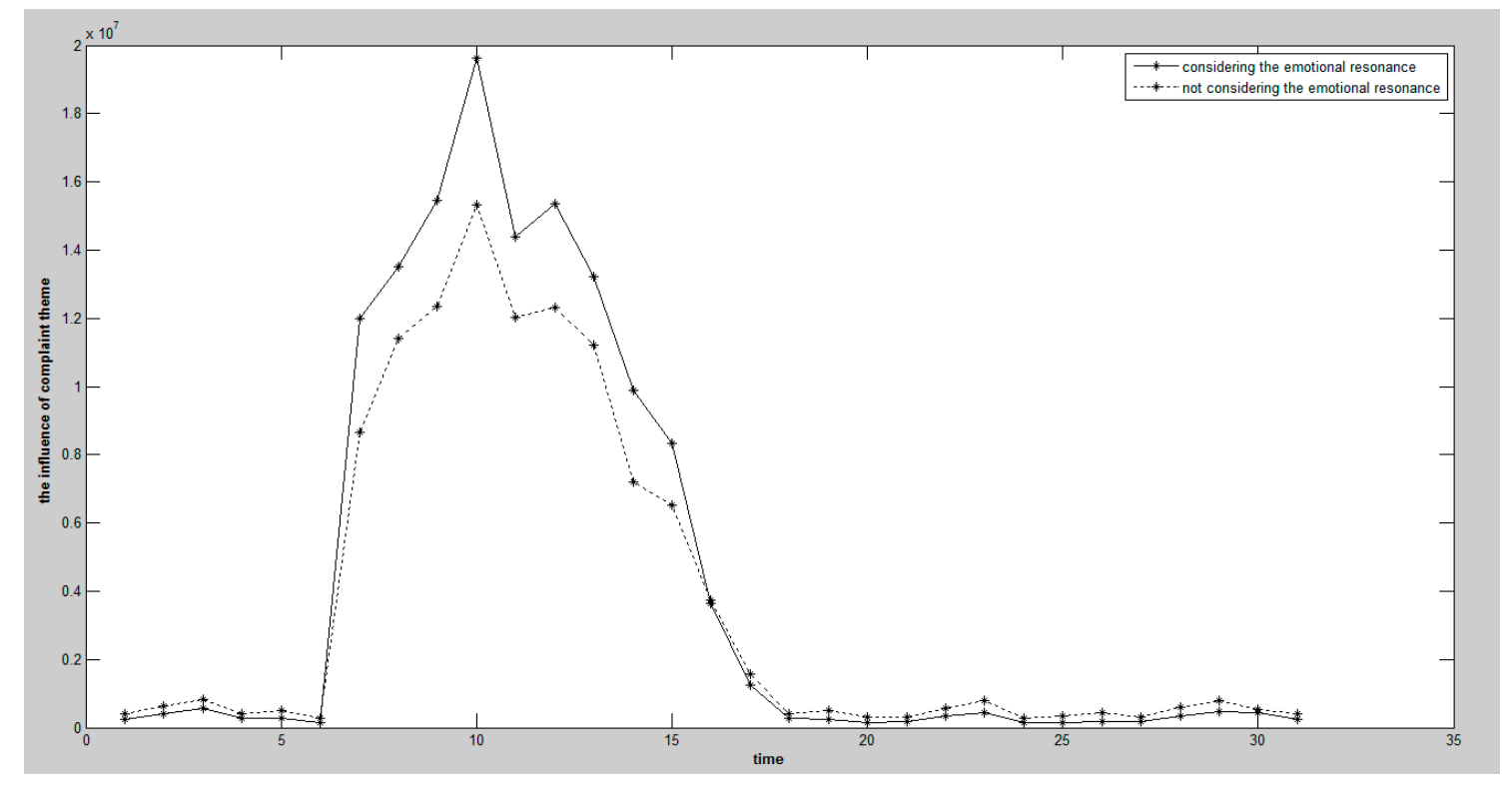

\subsection{Discussions of experimental results}

The complaints about "food security "are widespread online, as is shown in Figure 1, the influence value of group complaint is relatively small in the period without emergencies about it. When emergencies related to complaint theme occurred, such as "cadmium rice" event in May,2013," constant natural milk powder" event in August,2013," Taiwan Datong evil oil” event in October,2013 etc., the information about the topic related to used complaint theme increased, so that discourse influence of the complaint theme increased rapidly and reach the peak in a short time. This characteristic is different from the traditional environment of the complaint evolution which requires a period of fermentation time. Therefore, for online group complaint theme, it's necessary to establish a complaint listening mechanism, include network public opinion forecasting and crisis warning. If the netizens group complaint influence have a sudden increase, especially related emergencies occurred and caused social emotional resonance, public administration institution should enable the prevention and control plan, to prevent the emergency excited netizens group complaint which may lead to public crisis and information security issues.

As shown in the figure.2. and figure.3., if social emotional resonance related to compliant theme considered, the influence of group complaint will increase more rapidly and the peak value will higher. Because the emergency would remind netizen old memory of complaint and take old Microsoft topic up or strengthen it. Specially, if online opinion leaders with a large number of followers forward the information related complaint topic, more netizens will be gathered and join the topic discussion, present opinions and vent feelings frequently. Then, the polarized netizens emotion will form the social emotional resonance and enlarge the influence of group complaint theme topic further. Therefore, government publishes public information related to the complaint theme concerned by netizens, respond and give them feedback, will clarify what happened and resolve the complaint emotion. 
From the perspective, compared figure.2. to figure. 3 ,we find that different emergency will influence the online user emotion and social emotional resonance differently. In particular, the emergency related to complaint theme will cause social emotional resonance and enlarge the influence. In contrast, if the emergency is not associated with the complaint theme, the influence on complaint theme is litter or no. In addition, different emergencies have different effect in span and depth. Because of different quantity, character and social feature, influenced netizens recognize the correlation differently. If no one is deliberately, the non-associated emergency will not affect the influence of group complaint. It also illustrates that if emotional resonance not be considered, the influence value of group complaint will be similar. On the contrary, the influence value of group complaint can be differentiated clearly. In the same time, government can understand the social focus concerned by people through listening to online voice and set out public policy, which conform to the public and be scientific.

Through the analysis of experiment, the influence measure model of netizen group complaint can evaluate group complaint theme influence and obtain the influence value. The compute process of method is scientific and practical. In order to validate the effectiveness of model, the article compares the sort of different emergencies complaint theme influence with the data provided by Sina Weibo (http://data.weibo.com/index/hotword). Because we do not know about the data processing of Sina Weibo, we only compared the influence ranking and changing trend rather than the influence value. As a result, it agrees with Sina Weibo data center. The rationality and effectiveness of model could be proved.

\section{Conclusions}

On the online social network, more and more public information involving in public police decision and implement problem will be forming group complaint through information gathering, frequently interaction, word-of-mouth communication and emotional resonance, which play a important part in government public management decision. We build a online social network theme information and its influence measure model, from the following emotional resonance four aspects, such as group complaint information text quality, transmission timeliness user interaction degree and emergence development, based on information entropy theory. Through solution of this model, we can measure the influence of online group complaint theme. It could provide scientific basis for government public complaint scientific public decision and supply important theory basis and practical method for evaluating and supervising online group complaint. So this research have significant theoretical and practical value.

(1) on the online social network ,group complaint information influence will enlarge quickly ,through information gathering, frequently interaction, word-of-mouth communication and emotional resonance. The reason why online group complaint information influence generate and magnify is emergency information occurrence about complaint, tendentious opinion leader's attention and complaint mood guidance, the group with focusing complaint theme information active involve and frequent exchange and social mood resonance leaded by induce group complaint. So this paper build group complaint theme information influence measure index system, utilizing complaint text's quality, transmission timeliness user interaction degree and mood resonance of emergency. Based on this index 
system, we can build group complaint theme information dynamic measure model, which measure online complaint theme information influence.

(2)Through experiment whose data from Sina Weibo, we can verify that four-dimensional dynamic influence measure model of online group complaint theme information can solve effectively complaint information influence measure, which online group complaint. At the same time, we also find the emergency which is not related with complaint theme is hard induce complaint mood resonance. Even if the emergency linked with complaint theme leaded social mood resonance, its degree is also different. So this conclusion have a important practical value to make decisions and implement public policy.

(3)When there is some emergency related with complaint theme, the decision maker who is responsible for the public policy making and implementing could start complaint opinion monitoring and forewarning management, at the same time, timely feedback research information to the society. It can vanquish the negative effect made by group complaint mood. At the same time, management organization must pay attention to and track online opinion leaders abuse the right of speech. When the emergency happened, some opinion leaders who owned fans and influence of speech will emphasize and enlarge the influence of right. They can express information involving in their own tendentious opinion and interests, which leaded the topic develop to the way where benefit for them. Finally, it will enlarge social complaint resonance. To the opinion leaders who wants to get illegal interests and induce social mood resonance on purpose by relating to public complaint and emergency complaint events, it hurts social benefit and social security. The public policy management and decision organization must immediately evaluate and deal with these opinion leaders' illegal behavior.

Future studies could be considered from the following aspects. One is the relationship between netizens groups and complaint themes on online social network in a big data environment. Another is complaint themes influence measure method of different netizens groups with social emotional resonance. All these problems are important for the public information security management in the internet environment.

\section{Acknowledgments}

This work described in this paper was partially supported by Nation Science Foundation of China(71490725), the Ministry of Education of Humanities and Social Science Project(14YJA630015) and Anhui Provincial Natural Science Foundation(1408085MF115).

\section{Author Contributions}

Jianmin He proposed the study questions and strategy, designed research solution and revised the final edition.

Dongmin Tian determined the study questions and put them into practice, including data collection, analyses, processing and the experment.

Yezheng Liu confirmed the logical relation of research scheme and projected experiment. 


\section{Conflicts of Interest}

The authors declare no conflict of interest.

\section{References and Notes}

1. Qiu Hongfeng. The Social Amplification of Environmental Risks and the Communication Strategy of Local Governments: Rethinking the Xiamen PX Event. Journalism \& Communication 2013, 8, 105-117.

2. Wu Xiaohua; Lin Chunying. A method to measure the value of military intelligence. Journal of information 2006, 2, 65-69.

3. ZHAO Hong; WANG Can; HU Feng; WANG Yan; Determinants of Micro-blog's InfluenceBased on Micro-blog's Multilayer Structure. Chinese Journal of Management 2014, 11, 7, 10621068.

4. Luo Xin; A Communication-influence-power Evaluation Index System for Major Emergency Envents on Microblogs. Journalism \& Communication 2013, 3, 76-82.

5. Kien-Weng Tan; Jin-Cheon Na; Yin-Leng Theng; Influence detection between blog posts through blog features, content analysis, and community identity. Online Information Review 2011, 35, 3, 425-442.

6. Cha M; GUMMADI K P. Measuring user influence in Twitter: the million follower fallacy. Artificial Intelligence 2010, 146, 1, 10-17.

7. Jianmin He; Mengna Hu; Mingguang Shi; Yezheng Liu. Research on the measure method of complaint theme influence on online social network. Expert Systems with Applications 2014, 41, 6039-6046.

8. Zhu Li; Lv Benfu; Peng Geng. Study on the AHP-based evaluation system of personal blog influence. Mathematics in Practice and Theory 2008, 38, 15, 109-117.

9. Chien Chin Chen; You-De Tseng. Quality evaluation of product reviews using an information quality framework. Decision Support Systems 2011, 50, 755-768.

10. LIAO Cheng-lin; CAI Chun-jiang; LI Yi. An Empirical Study on Influence Factors of Online Reviews' Helpfulness in E-commerce. Soft Science 2013, 27, 5, 46-50.

11. Susan M. Mudambi; David Schuff. What Makes a Helpful Online Review? A Study of Customer Reviews on amazon.com. MIS Quarterly 2010, 1, 34, 185- 200.

12. Fu Kan; Qiu Wanhua. Research on bullwhip effect and simulation analysis based on timeliness entropy. Value Engineering 2008, 8, 13-14.

13. MA Jun; ZHOU Gang; XU Bin; HUANG Yong-zhong. Analysis of user influence in microblog based individual attribute features. Application Research of Computers 2013, 30, 8, 2483-2487.

14. Lin Chen. The Evaluation Model Research on Information Dissemination Influence of Microblog Individual. New Technology of Library and Information Service 2014, 2, 79-85.

15. Wang Junze; Wang Yalei; Yu Hang; Xu Xiaolin; Wang Guohua; Zeng Runxi; Study on the Recognition Model for Opinion Leader on Micro-blog. Journalism \& Communication 2011, 6 , $81-88$.

16. Jianmin He; Tao He; A Method of Evaluating the Influence of Topic in Oline Community Based on QFD. Information Science 2013, 31, 7, 96-99. 
17. YE Shaozhi; WU Felix; Measuring message propagation and social influence on twitter.com. Lecture Notes in Computer Science Author 2010, 6430, 216-231.

18. KWAK H; LEE Changhyun; PARK H et al. What is Twitter, a social network or a news media?. Proceedings of the 19th International Conference on World Wide Web(WWW'10). New York: ACM Press, 2010, 591-600.

19. LEE Changhyun; KWAK H; PARK H et al. Finding influentials based on temporal order of information adoption in twitter. Proceedings of the 19th International Conference on World Wide Web(WWW'10). New York: ACM Press, 2010, 1137-1138.

20. Zhu Li; Cao Zhenfei; The Emotional Resonance in Structure Box-The occurrence of the Mass Incident of Public Security. Social Science Research 2011, 4, 83-89.

21. N.J.Smelser; Theory of Collective Behavior. New York: Free Press 1963, 168-169.

22. Liu Xuemei. Thinking on the Research Framework of the Resonance Phenomenon of Public Opinion in Network Space.Journalism Lover 2011, 8, 32-33.

23. Herbert Blumer; Elementary Collective Behavior, in Alfred McClung Lee(ed.), New Outline of the Principles of Sociology, New York: Barnes \& Noble, Inc., 1946, 170-177.

24. Shannon C E. A Mathematical theory of communication. ACM SIGMOIBLE mobile computing and communications Review 2001, 5, 1, 3-55.

25. YANG Hong; YANG Shu-e; ZHANG Dong. On Measurement of the Information Disclosure Quality in Chinese Listed Companies Based on the Theory of Entropy. Systems Engineering 2007, 25, 9, 16-21.

26. Cheng Qiyue; Qiu Wanhua; Fu Yifeng. The method efficiency valuation studies in the command of process based on the system of the time efficacy entropy. Systems Engineering-Theory \& Practice 2008, 4, 155-158.

27. Ding Shifei; Zhu Hong; Xu Xinzheng; Shi Zhongzhi. Entropy-based fuzzy information measures. Chinese Journal of Computers 2012, 35, 4, 796-801.

28. CAI Zhengjie; LIANG Changyong; ZHAO Shuping. Research on emergency environmental accidents grade evaluation. Application Research of Computers 2014, 31, 11, 3217-3220.

29. XIE Chi; ZHONG Zan; Entropy Method and Its Application in Comprehensive Evaluation of Bank's Performance. China Soft Science 2002, 9, 108-110.

30. ZHANG Sui; ZHANG mei; CHI Guotai. The Science and Technology Evaluation Model Based on Entropy Weight and Empirical Research During the 10th Five-Year of China. Chinese Journal of Management 2010, 7, 1, 34-42.

(C) 2015 by the authors; licensee MDPI, Basel, Switzerland. This article is an open access article distributed under the terms and conditions of the Creative Commons Attribution license (http://creativecommons.org/licenses/by/3.0/). 